\title{
Comparisons of chlorophyll variability between the four major global eastern boundary currents
}

\author{
ANDREW C. THOMAS*†, P. TED STRUB $\$$, \\ MARY ELENA CARR $\S$ and RYAN WEATHERBEE $\dagger$ \\ $\dagger$ School of Marine Sciences, University of Maine, Orono, Maine 04469-5741, \\ USA \\ $\$$ College of Oceanic and Atmospheric Sciences, Oregon State University, \\ Corvallis, Oregon 97331-5503, USA \\ §Jet Propulsion Laboratory, California Institute of Technology, MS 300-323, \\ 4800 Oak Grove Dr., Pasadena, CA 91009-8099, USA
}

\begin{abstract}
The first two years of SeaWiFS (Sea viewing Wide Field of view Sensor) data (1997-1999) are used to document the variability of large-scale surface chlorophyll patterns within the coastal region along the full latitudinal extent of each of the four major global eastern boundary currents; the California, Humboldt, Benguela and Canary Currents. Seasonal chlorophyll patterns are compared to coincident seasonal cycles of Ekman transport calculated from satellite scatterometer data. In all four regions, maximum chlorophyll concentrations are generally temporally and latitudinally coincident with the seasonal maximum in upwelling (offshore Ekman transport) over most of their latitudinal range, but exceptions are documented. Interannual differences are evident in each region, most notably in the two Pacific regions where the 1997-1998 chlorophyll seasonality was affected by El Niño conditions. Significant differences between previously published chlorophyll seasonality deduced from the relatively sparse coverage of the Coastal Zone Color Scanner (CZCS) and the more complete coverage of SeaWiFS in both Southern Hemisphere regions are evident.
\end{abstract}

\section{Introduction}

The four major eastern boundary currents (EBCs), the California, Canary, Humboldt and Benguela Currents, are among the most biologically productive regions of the world's oceans, supporting large commercial fisheries. This productivity is a result of a dominant mean Equatorward coastal wind stress which results in offshore Ekman transport and upwelling of cold, nutrient-rich subsurface water along the shore which drives elevated primary productivity and results in high chlorophyll concentrations. The wind forcing varies seasonally and thus latitudinally over the range of each EBC region (Bakun and Nelson 1991) potentially producing strong seasonal and latitudinal variability in chlorophyll concentrations.

*e-mail: thomas@maine.edu

An updated version of a paper originally presented at Oceans from Space 'Venice 2000' Symposium, Venice, Italy, 9-13 October 2000. 
Superimposed on this latitudinal/seasonal variability are large interannual signals, most notably the El Niño Southern Oscillation. There are also local factors within each EBC region that impose both spatial and temporal variability, among which overall coastal orientation and the occurrence of headlands, the width of the shelf and the source of the upwelling water have been previously identified as having strong influences.

Such strong spatial and temporal variability, especially over the large geographical regions covered by the EBCs, makes direct comparisons of general patterns between the EBC regions difficult. Earlier attempts at intercomparisons using field data provided insight, but obviously suffered from unavoidable biases due to the time and location-specific nature of ship sampling, even within large research initiatives (e.g. Smith 1981). The Coastal Zone Color Scanner (CZCS) provided the first opportunity to use satellite ocean colour data to quantify synoptic scale variability of phytoplankton biomass over EBC regions. A comparison using these data between the Humboldt and the California Currents (Thomas et al. 1994) suggested distinct differences in the latitudinal relationships between chlorophyll and wind seasonal cycles. A comparison of phytoplankton pigment seasonal cycles from the CZCS data across all four EBC regions was provided by Hill et al. (1998). However, except over the California Current region, these data also suffer from serious biases due to data gaps. Many regions have large time-space windows with missing data. Even multi-year composite seasonal cycles are biased by the strong interannual variability characteristic of EBCs. In this study, the first two years of SeaWiFS data are used to provide a first, comprehensive quantification and comparison of the seasonal cycles of chlorophyll over global EBCs.

\section{Data and methods}

SeaWiFS data became available in September 1997. Daily, $4 \mathrm{~km}$ resolution data from each of the four EBC regions for the period September 1997 to August 1999 were processed to chlorophyll using current (2000) NASA coefficients (OC2v2, O'Reilly et al. 1998), remapped to a common projection and then formed into monthly composites. These monthly composites were then sub-sampled to calculate the mean chlorophyll concentration within a $100 \mathrm{~km}$ wide cross-shelf transect beginning at the coast at each latitude, over the entire latitudinal range of each EBC.

Wind forcing was calculated from monthly, re-gridded, wind vectors from the ERS/2 satellite. These data were sub-sampled over the latitudinal extent of each EBC to match the SeaWiFS data formed into alongshore wind stress and then used to calculate cross-shelf Ekman transport perpendicular to the coast.

\section{Results}

The two seasonal cycles (1997-1999) of mean chlorophyll concentration within the $100 \mathrm{~km}$ wide coastal region of each EBC region and the concurrent cross-shelf Ekman transport are shown in figure 1, contoured as a function of month and latitude. A distinct latitudinal/seasonal progression of both chlorophyll and wind forcing is evident in the Canary Current (figure $1(a)$ ) between $5^{\circ}$ and $35^{\circ} \mathrm{N}$. At lowest latitudes (south of $15^{\circ} \mathrm{N}$ ), where winds are dominated by seasonal shifts in the Intertropical Convergence Zone, winds are downwelling favourable in summer and associated with seasonal minima in chlorophyll. Maximum chlorophyll is present in winter associated with the seasonal shift to upwelling favourable winds. Progressing to higher latitudes, summer downwelling conditions cease and both the 
(a) Canary Current
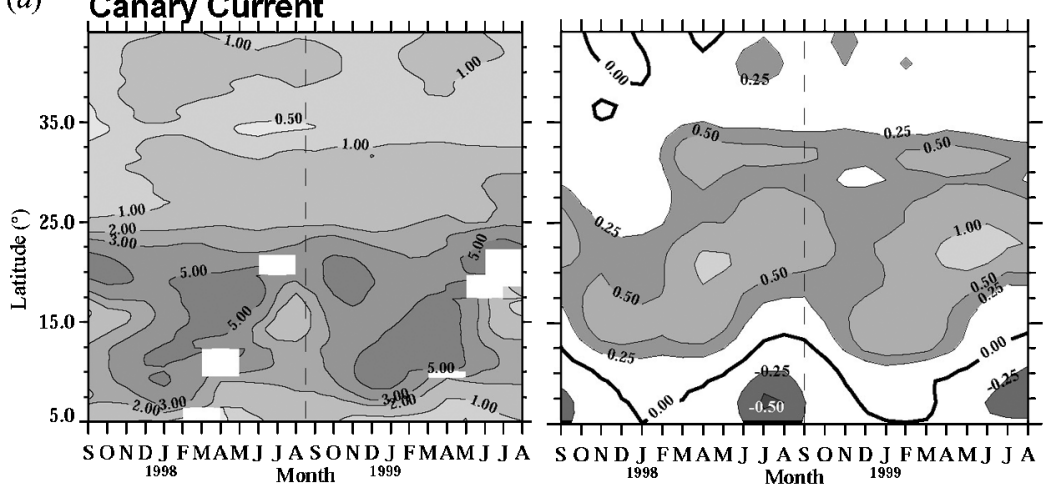

(b) California Current

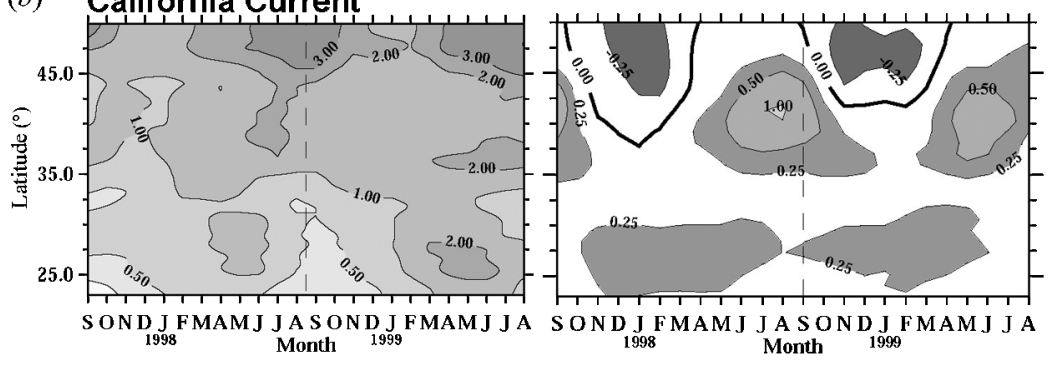

(c) Chile-Peru Current

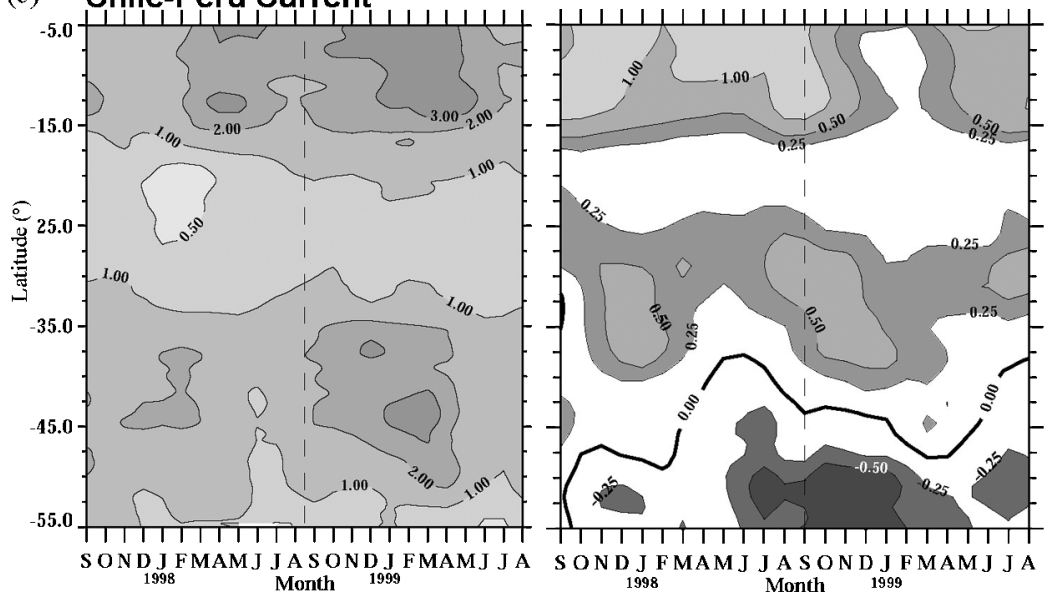

(d) Benguela Current

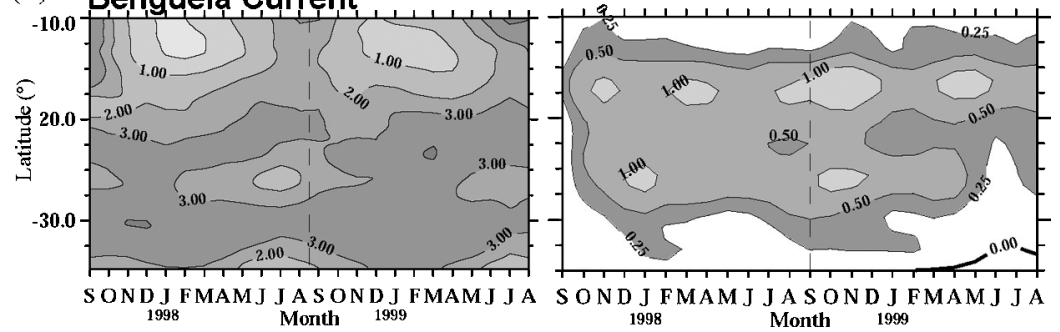

Figure 1. Contours of $100 \mathrm{~km}$ cross-shelf mean SeaWiFS chlorophyll (left panels, $\mathrm{mg} \mathrm{m}^{-3}$ ) and cross-shelf Ekman transport (right panels, $\mathrm{m}^{3} \mathrm{~s}^{-1} \mathrm{~m}^{-1}$, +offshore) as a function of time (months, September 1997-August 1999) and latitude in (a) the Canary Current $\left(5-43^{\circ} \mathrm{N}\right) ;(b)$ the California Current $\left(23-50^{\circ} \mathrm{N}\right) ;(c)$ in the Humboldt Current $\left(5-55^{\circ} \mathrm{S}\right)$; and $(d)$ the Benguela Current $\left(10-35^{\circ} \mathrm{S}\right)$. The dashed line separates the two available annual cycles of data. 
upwelling and chlorophyll maxima occur in phase and shift later into the season, consistent with known wind forcing patterns. Between ca $25^{\circ} \mathrm{N}$ and $35^{\circ} \mathrm{N}$, however, despite continued strong seasonality in wind forcing, the chlorophyll seasonal cycle is very weak. Off the Iberian peninsula (north of $35^{\circ} \mathrm{N}$ ), maximum chlorophyll is present in spring-early summer in both years, but seasonality is confused by strong interannual variability.

In the California Current (figure 1(b)), maximum chlorophyll concentrations are evident at highest latitudes $\left(>45^{\circ} \mathrm{N}\right)$, with seasonal maxima in spring and summer (April-September), minima in winter. Weaker seasonality is evident at mid latitudes $\left(35-45^{\circ} \mathrm{N}\right)$, although the maximums and minimums are still evident in summer and winter, respectively. A region of minimum chlorophyll seasonality exists at approximately $32^{\circ} \mathrm{N}$. South of this, maximum chlorophyll is again present in spring-summer. This seasonal cycle is in phase with the seasonal cycle of wind forcing, although strongest wind seasonality between $35^{\circ}$ and $45^{\circ} \mathrm{N}$ is not associated with a region of maximum chlorophyll seasonality. Conversely, although the seasonality of wind forcing at the lowest latitudes $\left(<30^{\circ} \mathrm{N}\right)$ is relatively weak, a strong seasonal cycle of chlorophyll is evident.

In the Humboldt Current off Peru $\left(5-15^{\circ} \mathrm{S}\right.$, figure $\left.1(c)\right)$ maximum chlorophyll concentrations are present in summer-autumn (January-May), apparently out of phase with wind forcing, but strong interannual variability in both signals makes interpretation difficult. Off Chile in the region $15-30^{\circ} \mathrm{S}$, minimum chlorophyll seasonality is evident, despite strong seasonality in wind forcing between $20^{\circ}$ and $30^{\circ} \mathrm{S}$. South of this, chlorophyll follows the canonical EBC seasonality, with maxima in hemispherical summer, minima in winter, in phase with the seasonal wind forcing. South of $45^{\circ} \mathrm{S}$, downwelling winds dominate. Strong interannual variability is evident throughout the latitudinal range of this EBC due to the 1997-1998 El Niño.

In the Benguela Current (figure $1(d)$ ) chlorophyll seasonality is strongest north of $20^{\circ} \mathrm{S}$ and not obviously coupled to the seasonality of wind forcing in these data. Two latitudinal regions exhibit elevated chlorophyll concentrations through most of the year; one centred at $23^{\circ} \mathrm{S}$ and the other centred at $30^{\circ} \mathrm{S}$. Seasonality of chlorophyll increases again south of $25^{\circ} \mathrm{S}$, in phase with wind forcing.

\section{Summary and conclusions}

SeaWiFS data provide the first comprehensive coverage of the full latitudinal and temporal variability of chlorophyll patterns in the four major global EBC upwelling regions. This allows systematic and quantitative comparisons to be made. Throughout most of their latitudinal extents, seasonal chlorophyll variability is in phase with seasonal wind forcing. Exceptions are evident within certain latitudinal ranges in each region. In all four regions, interannual variability is evident in the two years examined, most notably in the two Pacific EBCs (California and Humboldt), where the strong 1997-1998 El Niño event caused large hydrographic and biological anomalies (Chavez et al. 1999, Thomas et al. 2001). The most notable preliminary findings of this work are strong differences between chlorophyll seasonality in the two Southern Hemisphere EBC regions (Humboldt and Benguela) provided by the (previously available) temporally and spatially incomplete CZCS dataset (Thomas et al. 1994, Hill et al. 1998, Thomas 1999) and the more complete coverage offered by the SeaWiFS data presented here. Over large regions, SeaWiFS chlorophyll is in phase with wind forcing. Climatological monthly CZCS data in 
these two regions showed chlorophyll out of phase with wind forcing over large latitudinal arranges, likely a result of missing data.

\section{Acknowledgments}

Funding for ACT came from NASA grants NAG5-6558 and NAG5-6604 and NSF grants OCE-9711919 and OCE-0000899 (part of the US GLOBEC program). Funding for MEC was provided by the NASA Ocean Biogeochemistry Program and for PTS by JPL grant 958128 (TOPEX) and NASA grants NAG5-4947 (EOS) and NAG5-6604. GLOBEC contribution number 225.

\section{References}

BAKun, A., and Nelson, C. S., 1991, The seasonal cycle of wind stress curl in subtropical eastern boundary current regions. Journal of Physical Oceanography, 21, 1815-1834.

Chavez, F. P., Strutton, P. G., Friederich, G. E., Feely, R. A., Feldman, G. C., Foley, D. G., and MCFADEN, M. J., 1999, Biological and chemical response of the equatorial Pacific Ocean to the 1997-1998 El Niño. Science, 286, 2126-2131.

Hill, A. E., Hickey, B. M., Shillington, F. A., Strub, P. T., Brink, K. H., Barton, E. D., and Thomas, A. C., 1998, Eastern Boundary Currents: A Pan-Regional Review. In: The Sea, edited by A. R. Robinson and K. H. Brink (New York: J. Wiley and Sons Inc.), chapter 2.

O'Reilly, J. E., Maritorena, S., Mitchell, B. G., Seigal, D., Carder, K., Garver, S., KAHRU, M., and MCClain, C., 1998, Ocean color chlorophyll algorithms for SeaWiFS. Journal of Geophysical Research, 103, 24 937-24954.

SMITH, R. L., 1981, A comparison of the structure and variability of the flow field in three coastal upwelling regions: Oregon, northwest Africa and Peru, 1981. In Coastal Upwelling, edited by F. A. Richards (Washington D.C.: American Geophysical Union).

Thomas, A. C., 1999, Seasonal distributions of satellite-measured phytoplankton pigment concentration along the Chilean coast. Journal of Geophysical Research, 104, $25877-25890$.

Thomas, A. C., Blanco, J. L., Carr, M. E., Strub, P. T., and Ossus, J., 2001, Satellitemeasured chlorophyll and temperature variability off northern Chile during the 1996-1998 La Nina and El Niño. Journal of Geophysical Research, 106, 899-915.

Thomas, A. C., Strub, P. T., Huang, F., and James, C., 1994, A comparison of the seasonal and interannual variability of phytoplankton pigment concentrations in the Peru and California Current System. Journal of Geophysical Research, 99, 7355-7370. 